\title{
A Proposição de uma Taxonomia para Análise da Gestão Ambiental no Brasil
}

\author{
Sandra Simm Rohrich \\ João Carlos da Cunha
}

\begin{abstract}
Resumo
Este trabalho propõe uma taxonomia para sistemas de gestão ambiental de organizações industriais e analisa a relação da gestão ambiental com a inovação tecnológica adotada. As organizações têm demonstrado comportamentos diferenciados quanto às políticas de gestão, recursos aplicados e instrumentos de controle de gestão ambiental, mesmo quando têm um Sistema de Gestão Ambiental certificado. A pesquisa foi realizada em 37 organizações industriais no Brasil e os dados foram analisados com as técnicas de análise fatorial, o teste estatístico Kruskal-wallis e a análise de Clusters. O estudo propõe um modelo de seis fatores para análise da gestão ambiental nas empresas: controle, prevenção (formalização, crescimento, prevenção e cadeia de prevenção) e proatividade. As empresas pesquisadas, certificadas pela norma ISO 14.001, enquadraram-se em três grupos: controle, prevenção e proatividade. O modelo sugerido demonstrou ser válido como um aperfeiçoamento do modelo de classificação da política ambiental proposto por Hunt e Auster (1990). Os diversos grupos de empresas diferenciaram-se também em termos de comportamentos quanto às inovações tecnológicas de processo e origem das tecnologias adotadas.
\end{abstract}

Palavras-chave: gestão ambiental; inovação tecnológica; NBR ISO 14.001.

\begin{abstract}
Organizations have shown different behavior patterns in terms of the aspects concerning environmental management, even when they follow a certified system of environmental management according to NBR ISO 14.001. Such differences are present at the level of procedures, applied resources, control instruments and impacts related to other activities in the company. This work aims at the proposal of a taxonomy for the environmental management of industrial organizations, with a formal system of environmental management, and also the analysis of this environmental management with the adopted product and process technologies. A research was conducted in 37 industrial organizations in Brazil, and the quantitative analysis of the data used the factorial analysis technique, the Kruskal-wallis statistical test, and the cluster analysis. The results of this study allowed the improvement of the model of classification of companies in terms of environmental politics proposed by Hunt and Auster (1990). Six factors were identified for the analysis of the variable environmental management, characterized as control, prevention (formalization, growth, prevention and prevention chain) and proactivity. As for the companies, the cluster analysis allowed the identification of the three groups of companies: control, prevention and proactivity, which assigned more emphasis respectively to the control, prevention and proactivity factors, in increasing order of emphasis. These groups also showed various behavior patterns in terms of technological innovations of process, and origin of the adopted technologies.
\end{abstract}

Key words: environmental management; technology innovation; NBR ISO 14001. 


\section{INTRODUÇÃO}

Historicamente, países como o Brasil, em virtude do atraso em aspectos tecnológicos, educacionais e sociais (elevado grau de pobreza), priorizaram o crescimento sem preocupações com o meio ambiente. A exploração da natureza sobrepõe-se à mentalidade de preservação, encontrada nos países considerados de primeiro mundo. O Brasil tem visto a destruição ambiental como aceitável preço a ser pago pelo progresso econômico ou como uma prioridade menor considerando suas necessidades.

Os estudos que observaram a diversidade de empresas do setor produtivo brasileiro constataram grande diversidade de práticas de gestão ambiental. Estas podem variar de acordo com os tipos de produtos e processos de cada organização, assim como também são influenciadas por outros fatores relacionados ao porte, setor, região de atuação e inovações tecnológicas adotadas.

Em referência às inovações tecnológicas, Viegas e Fracasso (1998) afirmam que as empresas que aumentam continuamente a sua capacidade tecnológica estão mais aptas a adotarem o gerenciamento ambiental; porém há diferenças entre os países desenvolvidos e em desenvolvimento. No Brasil, por exemplo, prevalecem as tecnologias chamadas end-of-pipe ou fim de tubo, que tratam os resíduos e efluentes somente no final do processo produtivo, sendo consideradas tecnologias de controle. Schmidheiny (1992, p. 107) afirma que: “Apesar da aceitação geral da prevenção como prioridade máxima para a diminuição de resíduos, a maioria de recursos e esforços reguladores do governo estão ainda orientados no sentido de controle da poluição”.

De certa forma prevalecem ações corretivas na política ambiental brasileira, com a finalidade de cumprir a legislação, quanto a problemas ocasionados por acidentes ambientais; porém há indícios de que a gestão ambiental das organizações brasileiras está desenvolvendo-se e alcançando níveis que podem superar as ternologias de controle. Uma das demonstrações das mudanças que o Brasil está conquistando é o crescimento do número de organizações em busca de um Sistema de Gestão Ambiental.

Visando a analisar o tema exposto este trabalho teve como objetivos propor uma taxonomia para analisar a Gestão Ambiental em organizações industriais com um sistema de gestão ambiental formalizado e analisar o perfil das organizações industriais quanto às tecnologias de produto e de processo em relação ao padrão de gestão ambiental adotado. 


\section{A Gestão Ambiental}

Os estudos que envolvem a gestão ambiental, na maioria das vezes, trazem determinadas taxonomias, a fim de facilitar a compreensão da variável. Destacase o fato de serem identificados níveis diferentes de gestão ambiental, onde se percebem processos de evolução da questão ambiental dentro das organizações.

Muitas vezes são adotados modelos de classificação com três, quatro ou cinco níveis, para caracterizar a preocupação das empresas com os aspectos ambientais. Em todas essas classificações, três níveis se destacam. O primeiro nível corresponde ao controle da poluição, existindo a adaptação à regulamentação ou exigências de mercado. O segundo nível é o da prevenção que ocorre nas funções de produção, modificando-se os processos e/ou produtos. O terceiro nível caracteriza-se pela proatividade e integração do Controle Ambiental na Gestão Administrativa (Donaire, 1994; Maimon, 1994; Maimon, 1995).

Hunt e Auster (1990) descrevem cinco estágios no desenvolvimento de programas de gerenciamento ambiental, que vão desde a empresa iniciante, sem nenhuma preocupação ambiental, até a proatividade das empresas altamente comprometidas.

Segundo os autores o primeiro estágio envolve organizações que não possuem programas ambientais, ou possuem programas limitados por orçamentos ou relações que os tornam impotentes. O segundo estágio é formado por um pequeno staff centralizado, que auxilia na resolução das crises ambientais. No terceiro estágio, a organização considera que o máximo a ser feito pelo meio ambiente é a prevenção de acidentes. Não existe efetivamente um programa proativo de gestão ambiental. Existe um departamento ambiental, formado por especialistas como geólogos, químicos e biólogos, mas que não possuem influência nem autoridade para fazer mudanças efetivas. No quarto estágio, é dedicado tempo para gerenciar os problemas ambientais. Os departamentos ambientais têm experiência, financiamento e autoridade. Avaliam riscos, começam a desenvolver a educação ambiental e programas para treinar os trabalhadores chaves. No quinto estágio, as organizações possuem programas que se estendem por meio da corporação, educam os funcionários com informações e responsabilidade, monitoram as operações continuamente e são rápidos em resolver os problemas. Esse último pode ser observado como proativo, porquanto, segundo Sanches (2000), é observada a incorporação de fatores ambientais nas metas, políticas e estratégias da empresa, considerando os riscos e impactos ambientais não só de seus processos produtivos, mas também de seus produtos. 
Uma taxonomia proveniente de análises de autores na área econômica, Cromwell e Winpenny (1993) apud Gueorguieva e Bolt (2003), propôs uma estrutura para análise dos efeitos ambientais em quatro dimensões: cobertura espacial, escala de produção, mix de produtos e técnicas de produção. Essa proposta, diferentemente das anteriores, identifica aspectos diferentes e não excludentes. Em uma inter-relação das teorias anteriores com a proposta atual torna-se possível observar que as dimensões de Cromwell e Winpenny (1993) podem ser tanto corretivas, quanto preventivas ou proativas.

Kessler e Van Dorp (1998) propuseram uma taxonomia para avaliação das estratégias ambientais, cujas principais ênfases constatadas pelos autores são as seguintes:

a) A qualidade ambiental do solo, da água e das florestas.

b) A regulamentação ambiental ou funções estabilizadoras de recursos e as consequiências dos impactos na sociedade.

c) Conseqüências de longo prazo e limites à degradação ambiental para diferentes sistemas humanos, utilizando os recursos naturais.

Percebe-se que em todas as propostas é possível classificar as organizações em níveis diferentes quanto ao padrão de gestão ambiental adotado. Fatores como o respeito à legislação, por exemplo, geralmente são tratados como corretivos ou voltados ao controle da poluição. Já as mudanças em produtos e processos, ou a percepção da necessidade de longo prazo para as questões ambientais podem ser vistas como comportamento proativo em relação à gestão ambiental.

Desse modo, o presente trabalho buscou identificar essas diferenças quanto à importância dada aos fatores ambientais na gestão de algumas organizações localizadas no Brasil, porquanto, mesmo nas empresas que possuem certificação ISO 14.001, são encontradas especificidades no tratamento do problema.

\section{Princípios da Tecnologia Ambiental}

A Comissão Mundial para o Meio Ambiente e Desenvolvimento - CMMAD (1991) afirma alguns aspectos referentes às promessas e riscos das novas tecnologias: "A tecnologia continuará a mudar a tessitura social, econômica e cultural das nações e da comunidade mundial; as tecnologias novas oferecem grandes oportunidades para elevar a produtividade e os padrões de vida, melhorar a saúde e conservar as bases dos recursos naturais”. 
Acreditando na eficácia da inovação tecnológica, Barbieri (1997) argumenta que inovações ambientalmente saudáveis são aquelas que respeitam o meio ambiente e contribuem para ampliar a capacidade de suporte dos ecossistemas a que elas se aplicam.

As inovações tecnológicas de produto e de processo podem variar de acordo com a importância atribuída à gestão ambiental; quanto mais proativa a organização, mais inovações tecnológicas voltadas ao meio ambiente serão encontradas. "A preocupação ambiental deve resultar em ações que modifiquem o processo produtivo e o produto de maneira a torná-los menos impactantes sobre o meio ambiente" (Daroit e Nascimento, 2000, p. 2).

No mesmo sentido, Souza (1993) afirma que a agenda 21 é importante caminho na consecução da sustentabilidade ecológica e melhoria dos sistemas de produção. Isso deve ser obtido por meio de tecnologias e processos que utilizem recursos de forma eficiente e que minimizem os refugos durante o ciclo de vida do produto.

Daroit e Nascimento (2000) argumentam ainda a respeito do crescimento da conscientização ecológica, resultando em maiores exigências quanto ao desempenho ambiental dos produtos, além da legislação ambiental que pressiona ações nos processos e produtos. Assim, segundo os autores, essa realidade obriga as organizações a desenvolverem inovações ambientais chamadas de ecoinovações. Estas são observadas por Venzke (2002) como ecoeficientes, onde se torna possível identificar o equilíbrio entre a eficiência dos recursos e a responsabilidade ambiental.

Blumenfeld (1991), Quadro1, analisa o ciclo de vida dos produtos, considerando desde a aquisição de materiais, disposição de resíduos perigosos, disposição final do produto, enfocando a sua atenção para além do produto em si, ou seja, para a sua embalagem.

\section{Quadro 1: Ciclo de Vida do Produto}

\begin{tabular}{|c|l|}
\hline $\begin{array}{c}\text { Fases do ciclo de } \\
\text { vida }\end{array}$ & \multicolumn{1}{c|}{ Características } \\
\hline Design do produto & $\begin{array}{l}\text { Produtos, como os detergentes, passam a ser mais concentrados, utilizando embalagens } \\
\text { menores. }\end{array}$ \\
\hline $\begin{array}{c}\text { Fontes de matéria } \\
\text { prima }\end{array}$ & Utilização de recursos renováveis e fornecedores não poluidores \\
\hline $\begin{array}{c}\text { Produção, vendas e } \\
\text { distribuição }\end{array}$ & Eficiência energética, prevenção ou redução da poluição e minimização de resíduos \\
\hline Uso do produto & $\begin{array}{l}\text { Reduzir o impacto durante o uso do produto, como maior eficiência energética, redução } \\
\text { no consumo da água, produtos livre de CFC. }\end{array}$ \\
\hline Disposição final & $\begin{array}{l}\text { Preferência por materiais que possam ser reciclados ou reutilizados por meio de um } \\
\text { mercado secundário. }\end{array}$ \\
\hline
\end{tabular}

Fonte: Blumenfeld, 1991 (adaptado). 
Abarca et al. (1997) também abordam a importância da análise do ciclo de vida, posicionando-a como ferramenta para obter informações detalhadas para as áreas responsáveis no desenvolvimento de produtos.

Quanto aos processos, Fiksel (1996) caracteriza os processos mais limpos como aqueles em que há inovações tecnológicas, a fim de gerar menos poluição. Os produtos mais limpos seriam aqueles que geram menos poluição e lixo durante o seu ciclo de vida. O autor afirma que as inovações para os produtos vão além dos processos, porque, muitas vezes, exigem reconfiguração do processo produtivo, que está acima da aplicação de melhorias contínuas.

Neder (1992) propõe que as conseqüências tecnológicas dos processos possuem impactos em dois planos:

a) Troca de sistemas, máquinas e equipamentos, com eventual adoção de novas tecnologias de origem microeletrônica, novos materiais, biotecnologia visando direta e exclusivamente ao controle da poluição.

b) Processo produtivo mais amplo, no qual são alteradas as exigências técnicas e produtivas, gestão do trabalho e demais aspectos relacionados à modernização da base técnica.

É importante lembrar que, por serem predominantes as ações corretivas, grande parte das indústrias no país enfatiza mais a modernização da tecnologia de controle ambiental e menos o processo produtivo para melhorias ambientais. Entretanto, analisando as mudanças mais amplas no processo produtivo, aquelas cujas tecnologias aplicadas passam a ser consideradas limpas, as inovações tecnológicas voltadas ao meio ambiente se tornam duas: as de controle e as de prevenção (Pereira, Cunha e Pereira, 1997). Daroit e Nascimento (2000) consideram que as inovações de processo podem ser opções de fim de tubo ou tecnologias que resultem em produção mais limpa, porém ressaltando que as soluções fim de tubo se vêm revelando insuficientes. Os autores ainda ressaltam que as tecnologias de produção mais limpa podem reduzir os custos com investimentos em tecnologias caras e complexas de tratamento de fim de tubo, além de cumprirem a legislação ambiental.

Desse modo, o caso clássico de uma tecnologia limpa de controle são as Estações de Tratamento de Efluentes (ETE). Os autores citados demonstram parecer natural que a organização adote primeiramente a tecnologia de controle, para depois alcançar a de prevenção, como, por exemplo, a redução de produtos químicos e metais pesados no processo de produção.

Como tecnologias limpas, os autores citam todas as tecnologias utilizadas na 
produção de bens e serviços que não destroem o meio ambiente. Por exemplo: 1) reciclagem de papel, latas, entre outros; 2) uso de energias alternativas, como a eólica, solar, biomassa e células fotovoltaicas; 3) produtos biodegradáveis; 4) tecnologias para redução e prevenção da poluição do ar, das águas, do solo ou a sonora, ou dos resíduos sólidos e a visual.

North (1997) apresenta uma metodologia para P\&D: pesquisa e desenvolvimento de produtos e processos ecológicos, a qual pode ser utilizada no gerenciamento da inovação tecnológica.

\section{Quadro 2: Inovação Tecnológica para Produtos e Processos Ecológicos}

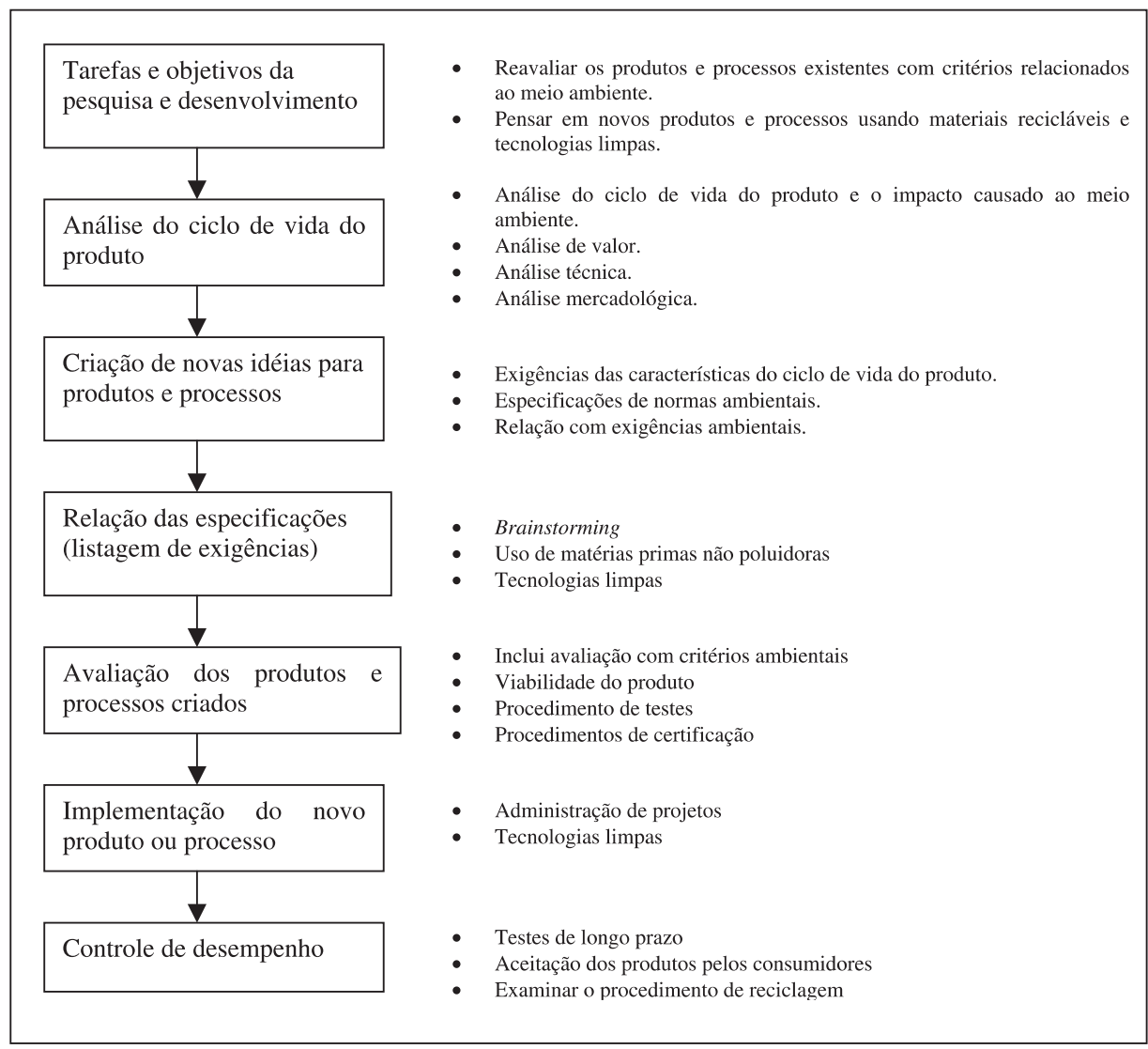

Fonte: metodologia do P\&D para produtos e processos ecológicos (North, 1997).

A preocupação em torno das questões ambientais evidencia que a introdução de tecnologias ecologicamente mais adequadas passam a ser vistas pelas empresas não apenas como estratégia preventiva, mas também como vantagem de mercado altamente competitiva, permitindo que elas usem mais produtivamente uma série 
de insumos. O desempenho ambiental do setor industrial está associado, portanto, ao desafio de produzir mais, utilizando menos recursos (Oashi e Simon, 1997).

\section{Metodologia do Estudo}

A população da pesquisa abrangeu todas as indústrias localizadas no Brasil que possuíam um Sistema de Gestão Ambiental formalizado e certificado pela norma NBR ISO 14.001 até junho de 2000. Essa população compunha um total de 149 organizações, segundo o Comitê Brasileiro de Gestão Ambiental, vinculado à Associação Brasileira de Normas Técnicas - ABNT.

Foi utilizada uma amostra não probabilística por conveniência. Inicialmente a intenção foi enviar os questionários para todas as empresas da população; porém, devido à dificuldade na obtenção dos dados das empresas e respectivos contatos, foram enviados questionários para 62 empresas do total de 149. Os questionários foram respondidos pelos responsáveis pela área de gestão ambiental das organizações. Como retorno foi obtido um total de 37 questionários válidos, ou seja, 59\% da amostra.

Assim, os dados primários foram obtidos por meio de questionário estruturado, composto de perguntas fechadas, construídas com base em escala de cinco pontos do tipo Likert. Os objetivos do estudo foram os dois seguintes:

a) propor uma taxonomia para analisar a Gestão Ambiental em organizações industriais com um sistema de gestão ambiental formalizado e localizadas no Brasil;

b) analisar o perfil das organizações industriais quanto às tecnologias de produto e de processo em relação ao padrão de gestão ambiental adotado.

\section{Análise dos Dados}

Como procedimento para estruturar a investigação foram formuladas as quatro hipóteses seguintes:

H1) A gestão ambiental, de acordo com o grau de importância dada às questões relativas ao meio ambiente, pode ser caracterizada como controle, preventiva ou 
proativa. Para verificar esta primeira hipótese de pesquisa, utilizou-se a análise fatorial.

H2) Organizações que possuem um Sistema de Gestão Ambiental, caracterizado por controle, prevenção ou proatividade, enfatizam, de modo diferenciado, as inovações tecnológicas de processos.

H3) Organizações que possuem um Sistema de Gestão Ambiental, caracterizado por controle, prevenção ou proatividade, enfatizam, de modo diferenciado, as inovações tecnológicas de produtos.

H4) Organizações que possuem um Sistema de Gestão Ambiental, caracterizado por controle, prevenção ou proatividade, enfatizam, de modo diferenciado, a origem da tecnologia.

A verificação das hipóteses de número 2, 3 e 4 foi realizada por meio do teste estatístico denominado Análise de Cluster, que possibilita a verificação da formação de grupos de empresas com propriedades em comum. Foi realizado o teste partindo-se do agrupamento da variável gestão ambiental em grupos de empresas com comportamentos semelhantes quanto às variáveis da gestão ambiental. Com a obtenção dos Clusters, a verificação de diferenças entre os grupos foi realizada pela aplicação do teste Kruskal-Wallis. Após a confirmação das diferenças, a análise de cada fator foi realizada com base nos valores da moda de cada item analisado.

Para testar as hipóteses, foram aplicadas as conclusões de Rohrich (2001); este, mediante análise fatorial, encontrou, entre outros fatores, três que podem ser empregados para classificar as inovações tecnológicas voltadas ao meio ambiente: produtos, processos e origem da tecnologia:

\begin{tabular}{|l|l|}
\hline \multicolumn{1}{|c|}{ PROCESSO } & \multicolumn{1}{|c|}{ ORIGEM DA TECNOLOGIA } \\
\hline $\begin{array}{l}\text { 1.Tecnologias de controle e redução dos níveis de } \\
\text { poluição. }\end{array}$ & $\begin{array}{l}\text { 1. As inovações tecnológicas são predominantemente } \\
\text { de origem externa. }\end{array}$ \\
\hline $\begin{array}{l}\text { 2. Inovações consideradas de alta tecnologia visando ao } \\
\text { controle da poluição. }\end{array}$ & \multicolumn{1}{|c|}{ PRODUTOS } \\
\hline $\begin{array}{l}\text { 3. Mudanças nos processos ou na composição dos } \\
\text { produtos finais da empresa. }\end{array}$ & $\begin{array}{l}\text { 1. Responsabilidade ambiental como fabricante do } \\
\text { produto após a sua venda e consumo. }\end{array}$ \\
\hline $\begin{array}{l}\text { 4. As tecnologias possibilitam a utilização de materiais } \\
\text { alternativos. }\end{array}$ & $\begin{array}{l}\text { 2. Reduzir o impacto durante o uso dos produtos } \\
\text { (eficiência energética, consumo de água, design, } \\
\text { embalagem, entre outros) }\end{array}$ \\
\hline $\begin{array}{l}\text { 5. A reutilização da água na produção como prática } \\
\text { sistematicamente adotada pela empresa. }\end{array}$ & \\
\hline
\end{tabular}




\section{Análise da Gestão Ambiental}

Analisando a hipótese $\mathrm{H} 1$ a análise fatorial verificou 19 variáveis da escala aplicada no questionário e agrupadas em 6 fatores, explicando 77,38\% da variância total, conforme Tabela 1. Para testar a correlação entre as variáveis foi utilizado o teste KMO (Kaiser-Meyer-Olkin) e Bartlett.

Resultados encontrados:

Kaiser-Meyer-Olkin - Medição da adequação da amostra $\quad 0,540$

Teste de Bartlett's 449,894

Sig. $\quad 0,000$

\section{Tabela 1: Dimensões da Gestão Ambiental}

\begin{tabular}{|c|c|c|c|c|c|}
\hline Fator & $\begin{array}{c}\text { Número de itens } \\
\text { indicados }\end{array}$ & Autovalor & $\begin{array}{c}\text { \% da variância } \\
\text { explicada }\end{array}$ & $\begin{array}{c}\text { \% da variância } \\
\text { explicada } \\
\text { acumulada }\end{array}$ & $\begin{array}{c}\text { Coeficiente } \\
\text { alfa }\end{array}$ \\
\hline F1 & 5 & 5,69 & 29,94 & 29,94 & 0,8176 \\
F2 & 3 & 2,69 & 14,17 & 44,11 & 0,8670 \\
F3 & 3 & 2,15 & 11,30 & 55,41 & 0,6861 \\
F4 & 3 & 1,96 & 10,32 & 65,73 & 0,7026 \\
F5 & 2 & 1,17 & 6,14 & 71,87 & 0,5948 \\
F6 & 3 & 1,05 & 5,51 & 77,38 & 0,6276 \\
\hline
\end{tabular}

\section{Dimensões Identificadas}

Tabela 2: Itens Componentes do Fator Proatividade

\begin{tabular}{|l|c|c|}
\hline \multicolumn{1}{|c|}{ Itens } & Carregamento & Coeficiente alfa \\
\hline 1. Tratamento de resíduos e efluentes & $-0,704$ & \\
\cline { 1 - 2 } 2. A alta gerência participa da gestão ambiental & 0,786 & \\
\cline { 1 - 2 } 3. Autoridade formal para realizar as mudanças que considerar necessárias. & \multirow{2}{*}{0,8176} \\
\cline { 1 - 2 } 4. Influência na formulação de suas estratégias. & 0,759 & 0,684 \\
\cline { 1 - 2 } 5. Programa de educação ambiental. & 0,682 & \\
\hline
\end{tabular}

Nesse fator, o item que variou inversamente refere-se à preocupação da gestão ambiental com o tratamento de resíduos e efluentes. Esta não é preocupação da proatividade, pois estaria mais voltada às questões de controle da poluição. Pertencem ao fator proatividade a autoridade formal designada por função específica; a participação dos objetivos ambientais na formulação das estratégias e a existência de programas de educação ambiental.

\section{Tabela 3: Itens Componentes do Fator Prevenção para a Comunidade}

\begin{tabular}{|l|c|c|}
\hline Itens & Carregamento & Coeficiente alfa \\
\hline 1. Pesquisa a opinião da comunidade local/ impactos sociais. & 0,860 & \multirow{2}{*}{0,8670} \\
\cline { 1 - 2 } 2. Área de gestão ambiental formada por especialistas ambientais. & 0,855 & \multirow{2}{*}{0,862} \\
\cline { 1 - 2 } 3. As práticas ambientais da organização são divulgadas à comunidade. & 0,862 & \\
\hline
\end{tabular}


Esse fator enfatiza as questões voltadas à opinião da comunidade em relação às conseqüências das atividades organizacionais para o meio ambiente. A presença de especialistas ambientais também se caracteriza como prevenção, conforme constatado por Hunt e Auster (1990).

\section{Tabela 4: Itens Componentes do Fator Prevenção para a Formalização}

\begin{tabular}{|l|c|c|}
\hline Itens & Carregamento & Coeficiente alfa \\
\hline 1. Área de gestão ambiental formula relatórios periódicos. & 0,664 & \multirow{2}{*}{0} \\
\cline { 1 - 2 } 2. Programa para prevenção de acidentes ou impactos ambientais. & 0,757 & \multirow{2}{*}{0,6861} \\
\hline 3. Há um programa sistemático de auditorias ambientais. & 0,825 & \\
\hline
\end{tabular}

Identificado como prevenção para a formalização, enfatiza eventos formais, como a elaboração de relatórios escritos e a adoção de auditorias ambientais periódicas.

\section{Tabela 5: Itens Componentes do Fator Prevenção para o Crescimento}

\begin{tabular}{|l|c|c|}
\hline \multicolumn{1}{|c|}{ Itens } & Carregamento & Coeficiente alfa \\
\cline { 1 - 2 } 1. Orçamento anual específico para as atividades de gestão ambiental. & 0,746 & \\
\cline { 1 - 2 } 2. Gestão ambiental participa da adoção de inovações tecnológicas. & 0,731 & \multirow{2}{*}{0,7026} \\
\cline { 1 - 2 } 3. Gestão ambiental influencia decisão de compra de seus consumidores. & 0,745 & \\
\hline
\end{tabular}

As influências do ambiente externo passam a ser mais consideradas a partir do fator prevenção para o crescimento, onde se destacam a influência dos consumidores, a adoção de inovações tecnológicas e a previsão de orçamentos para a gestão ambiental.

\section{Tabela 6: Itens Componentes do Fator Cadeia de Prevenção}

\begin{tabular}{|l|c|c|}
\hline \multicolumn{1}{|c|}{ Itens } & Carregamento & Coeficiente Alfa \\
\hline 1. Exigências a fornecedores em relação às características ambientais. & 0,859 & \multirow{2}{*}{0,5948} \\
\cline { 1 - 2 } 2. O desempenho ambiental é divulgado para todas as demais áreas. & 0,597 & \\
\hline
\end{tabular}

Interpretado como cadeia de prevenção, primeiramente a organização faz exigências aos seus fornecedores e, internamente, divulga as suas práticas para toda a organização.

\section{Tabela 7: Itens Componentes do Fator Controle}

\begin{tabular}{|c|c|c|}
\hline Itens & Carregamento & Coeficiente alfa \\
\hline 1. A empresa monitora os níveis de poluição liberados. & 0,582 & \multirow{3}{*}{0,6276} \\
\hline 2. Cumpre as legislações relativas ao meio ambiente e cabíveis ao seu setor. & 0,501 & \\
\hline 3. Gestão ambiental possui envolvimento com produção/manufatura. & 0,889 & \\
\hline
\end{tabular}


Conforme pode ser verificado na Tabela 7, o controle dos níveis da gestão ambiental geralmente é realizado mediante algumas práticas comuns: medição dos níveis de poluição, cumprimento de legislação e envolvimento com a área produtiva, principalmente para aplicação de tecnologias end of pipe, ou fim de tubo.

\section{Formação de Grupos de Empresas com Propriedades em Comum}

Utilizou-se a análise de Cluster para testar as hipóteses da H2 à H4. Optouse pelo método hierárquico, a fim de descobrir o comportamento dos grupos de empresas quanto à variável gestão ambiental.

Para verificar se os grupos encontrados em relação à variável gestão ambiental eram iguais ou diferentes, utilizou-se o teste não paramétrico denominado KruskallWallis, que foi adequado para confirmar as diferenças.

\section{Identificação dos Clusters}

Para identificação dos clusters encontrados na análise foram observados alguns dados descritivos dos clusters, com base nos valores das modas obtidas nas respostas de cada item, a fim de identificá-los conforme os seus comportamentos em relação às variáveis gestão ambiental.

O primeiro cluster, formado por onze empresas, ficou denominado Grupo Proativo, pois as empresas que representam este grupo são as que possuem as características ambientais nos níveis mais elevados das análises. Nos itens referentes aos fatores, prevenção para a formalização e proatividade em relação às características ambientais, as empresas desse grupo apresentaram os maiores escores possíveis no estudo. Nos itens referentes aos fatores prevenção para a comunidade, prevenção para o crescimento e cadeia de prevenção, o grupo atingiu os maiores escores do estudo, embora não tenham sido o máximo possível.

O segundo cluster, com quinze empresas, denominado Grupo Preventivo, obteve escores inferiores na prevenção para a comunidade, tratando-se principalmente de pesquisas de opinião da comunidade e divulgação de práticas ambientais na comunidade. Os escores do grupo também são inferiores ao proativo quanto à prevenção para o crescimento, pois o grupo exerce menos influência no processo de decisão de compra de seus clientes, em relação a características ambientais. Em relação ao fator cadeia de prevenção, o grupo está fazendo menos exigências a seus fornecedores quanto a características ambientais. 
O terceiro cluster, com onze empresas, Grupo Controle, devido à obtenção dos maiores escores possíveis nos fatores controle e formalização. Em relação à proatividade, o grupo não possui autoridade formal para todas as situações ambientais. No fator prevenção para a comunidade, o grupo apresentou escores muito reduzidos, demonstrando poucas pesquisas em relação à opinião da comunidade. Quanto às práticas ambientais adotadas pelas organizações, não há especialistas ambientais em todas as organizações e também não há suficiente divulgação das práticas ambientais na comunidade.

\section{Figura 1: Grupo de Empresas com Propriedades em Comum}

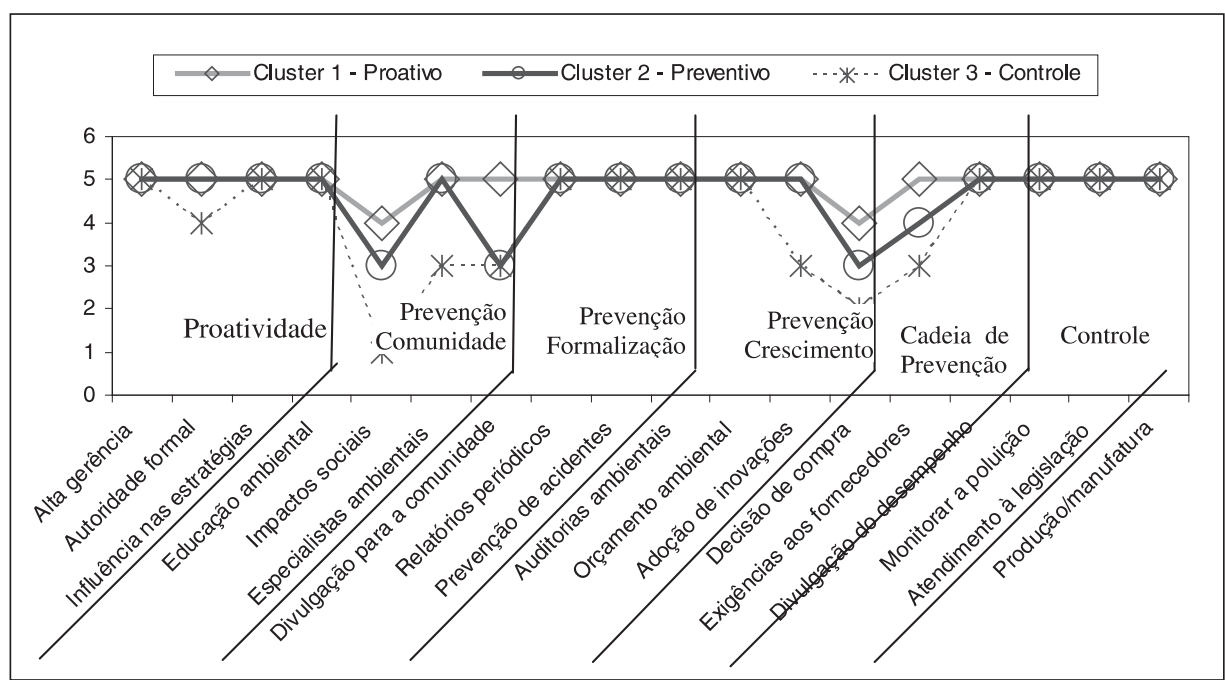

\section{Verificação das Hipóteses da H2 a H4}

Esta hipótese objetivou verificar se as organizações que possuem um Sistema de Gestão Ambiental, caracterizado por controle, prevenção (comunidade, formalização, crescimento, cadeia de prevenção) ou proatividade, enfatizam de modo diferenciado as inovações tecnológicas para controle de processos.

Essa hipótese foi aceita de acordo com a observação dos diferentes comportamentos apresentados pelos grupos Proativo, Preventivo e Controle, evidenciado no teste Kruskal-Wallis, cujas significâncias obtidas foram: 0,026; 0,002; 0,139; 0,001 e 0,006; comprovou-se, assim, a diferença entre os grupos.

A avaliação se as organizações que possuem um Sistema de Gestão Ambiental, caracterizado por controle, prevenção (comunidade, formalização, crescimento, cadeia de prevenção) ou proatividade, enfatizam de modo diferenciado as inovações tecnológicas de produtos. 
Essa hipótese foi rejeitada, considerando que não há diferentes ênfases em relação às inovações tecnológicas de produtos para os Grupos Proativo, Preventivo e Controle, conforme se observou na significância obtida no teste Kruskal-Wallis, cujas significâncias obtidas foram: 0,357 e 0,321; não demonstrando diferença entre os grupos.

Avaliando a quarta hipótese, se as organizações que possuem um Sistema de Gestão Ambiental, caracterizado por controle, prevenção (comunidade, formalização, crescimento, cadeia de prevenção) ou proatividade, enfatizam de modo diferenciado a origem das tecnologias, constatou-se que essa hipótese pode ser confirmada em relação à diversidade de comportamentos, apresentados pelos grupos proativo, preventivo e controle e pela confirmação das diferenças observadas no teste Kruskal-Wallis 0,046.

\section{Figura 2: Inovações Tecnológicas Voltadas ao Meio Ambiente}

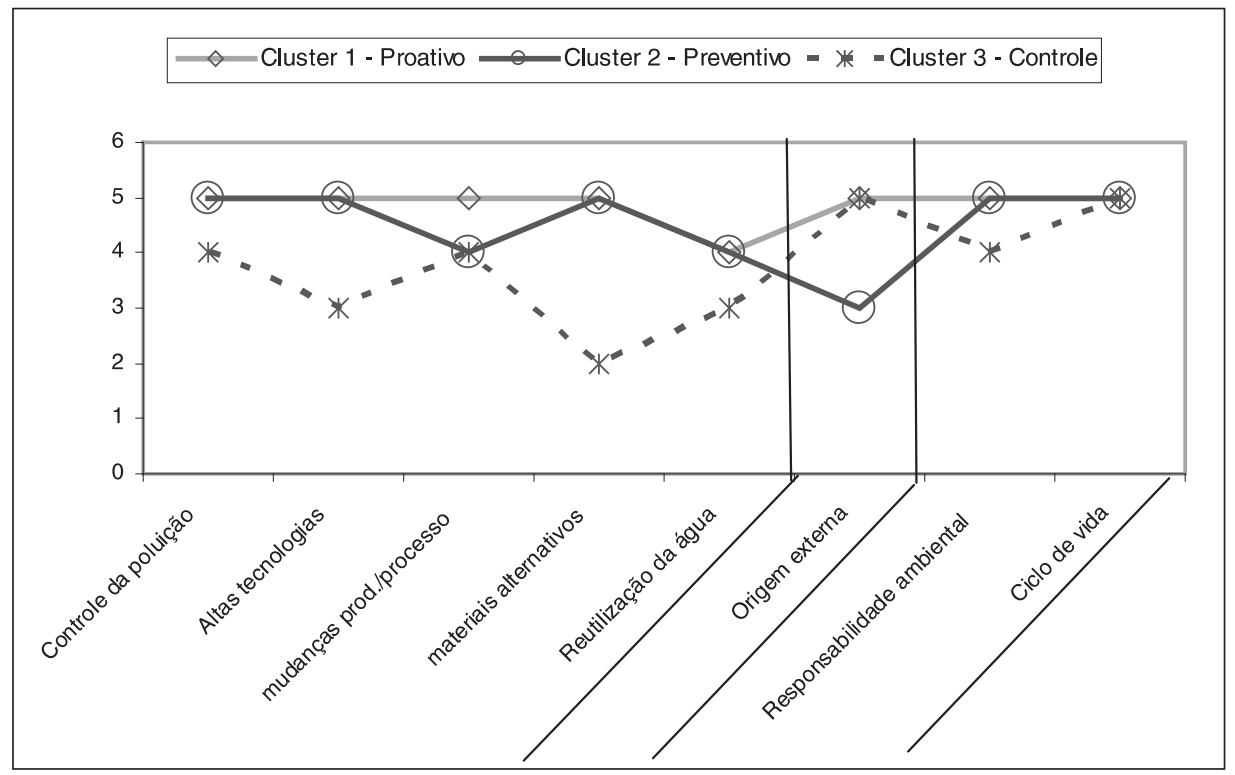

Verifica-se que os clusters analisados são diferentes quanto às inovações tecnológicas de processo, principalmente nos itens relativos às altas tecnologias e utilização de materiais alternativos. Na origem das inovações tecnológicas, evidenciou-se que para as organizações pertencentes aos clusters proativo e controle a maioria de suas inovações tecnológicas são de origem externa, sendo possível considerar que essas empresas não desenvolvem suas próprias tecnologias. Quanto às inovações tecnológicas de produto, apenas no item que se refere à responsabilidade ambiental o grupo considerado como controle obteve menor 
êxito. Contudo, no item que analisou a importância dada ao ciclo de vida dos produtos, os três grupos assinalaram para o índice cinco na escala de Likert, de modo que esta análise seria realizada em todos os tipos de empresas pesquisadas.

\section{Conclusões}

As organizações localizadas no Brasil têm demonstrado diferentes comportamentos quanto aos aspectos que tangem à gestão ambiental. Mesmo nos casos em que se observa a existência de um Sistema de Gestão Ambiental certificado conforme a NBR ISO 14.001, há diferenças consideráveis entre as organizações.

Este trabalho tomou por base outros que procuraram delinear taxonomias para a gestão ambiental, de modo que os principais autores referenciados na construção desta taxonomia foram Hunt e Auter (1990). Como metodologia optou-se pela análise fatorial, onde foram identificados seis fatores para análise da variável gestão ambiental. Estes foram caracterizados como controle, prevenção (formalização, crescimento, prevenção e cadeia de prevenção) e proatividade.

Quanto às empresas, a análise de cluster permitiu evidenciar três grupos de empresas: controle, prevenção e proatividade. Esta classificação está montada em ordem crescente de preocupação e ação efetiva das empresas em relação ao meio ambiente. As empresas pertencentes ao grupo proativo seriam as que adotaram as melhores práticas ambientais, enquanto o grupo denominado controle é o que adotou as práticas mais simples.

Evidenciou-se que as organizações consideradas proativas são aquelas que têm como diferencial a análise dos possíveis impactos sociais de suas atividades e a divulgação de suas práticas na comunidade. Nesse grupo as empresas, na sua maioria, analisam o processo de decisão de compra dos consumidores e as possíveis influências dos atributos ambientais, aspectos pouco praticados pelos grupos prevenção e controle. Esses grupos também demonstraram comportamentos diversos quanto às inovações tecnológicas de processo e origem das tecnologias adotadas.

Do ponto de vista das inovações tecnológicas, o grupo proativo destaca-se principalmente pela mudança das características dos processos ou composição final dos produtos, o que ressalta a afirmação a respeito da influência no processo de decisão de compra do consumidor, quanto aos possíveis atributos ambientais. Quanto à origem das tecnologias foram verificadas duas situações: a primeira diz 
respeito aos grupos proativo e controle, que em ambos os casos, as tecnologias empregadas são, na maior parte das vezes, de origem externa, talvez porque nacionalmente ainda não haja o domínio tecnológico para abranger todo o mercado, observação que pode ser aprofundada em outras pesquisas.

Nas inovações tecnológicas de produtos, os três grupos têm comportamentos semelhantes quanto à análise do ciclo de vida; todavia, no item que trata da responsabilidade ambiental após a venda e consumo, a ênfase se deu gradualmente: o grupo proativo apresentou desempenho superior ao preventivo e este ao controle.

Estudos futuros poderão ser realizados, buscando maior aprofundamento por meio de entrevistas pessoais com os responsáveis pelas áreas de gestão ambiental, o que poderia ser feito mediante a utilização de outras metodologias mais voltadas a análises qualitativas; a extensão desse estudo para populações maiores seria mais uma forma para conseguir a generalização de algumas conclusões percebidas.

\section{Artigo recebido em 03.05.2003. Aprovado em 15.04.2004.}

\section{ReferênCIAs Bibliográficas}

ABARCA, C. D. G. et al. ISO 14000 - Análisis del ciclo de vida. In: ENCONTRO NACIONAL DE ENGENHARIA DE PRODUÇÃO, 17., 1997, Gramado. Anais... Gramado: ENEGEP, 1997.CD-ROM.

\section{BARBIERI, J. C.}

Políticas públicas indutoras de inovações tecnológicas ambientalmente saudáveis nas empresas. Revista de Administração Pública, São Paulo, v. 31, n. 2, p. 135-52, mar/ abr. 1997.

\section{BLUMENFELD, $\mathrm{K}$.}

Managing the product life cycle. Management Review, v. 80, n.3, p. 3032, mar., 1991.
COMISSÃO MUNDIAL SOBRE MEIO AMBIENTE E DESENVOLVIMENTO (CMMAD).

Nosso futuro comum. 2. ed. Rio de Janeiro: Fundação Getúlio Vargas, 1991.

DAROIT, D.;

NASCIMENTO, L. F.

A busca da qualidade ambiental como incentivo à produção de inovações. In: ENCONTROANUALDAANPAD, 24., 2000, Florianópolis. Anais... Florianópolis: ANPAD, 2000. 1 CDROM.

DONAIRE, D.

Considerações sobre a influência da variável ambiental na empresa. Revista de Administração de Empresas, São Paulo, v. 34, n. 2, p. 68-77, mar./abr. 1994. 
GUEORGUIEVA,A.;

BOLT, K.

A critical review of the literature on structural adjustment and the environment. Environmental Economics Series, Washington, D.C., April, 2003. Disponível em: < http:\|www.worldbank.> .(Org.). Acesso em: 15 sept. 2003.

HUNT, C. B.;

AUSTER, E. R.

Proactive environmental management: avoiding the toxic trap. Sloan Management Review, EUA: Putnam, Hayes \& Bartlett, Winter 1990.

\section{KESSLER, I.;}

\section{VAN DORP, M.}

Structural adjustment and the environment: the need for an analytical methodology. In: Ecological economic, 27, p. 267-281, 1998. Disponível em: <http:॥www.worldbank.org.> Acesso em: 15 sept. 2003

\section{MAIMON, D.}

Eco-estratégia nas empresas brasileiras: realidade ou discurso? Revista de Administração de Empresas, São Paulo, v. 34, n. 4, p. 119-130, jul./ago., 1994.

Responsabilidade ambiental das empresas brasileiras: realidade ou discurso? In: CAVALCANTI, C. Desenvolvimento e natureza: estudos para uma sociedade sustentável. São Paulo: Cortez, 1995.

\section{NEDER, R.T.}

Há política ambiental para a indústria brasileira? Revista de Administração de Empresas, São Paulo, v. 32, n. 6, p. 6-13, Abr./Jun. 1992.
PEREIRA, M. F;

CUNHA, M. S.;

PEREIRA, L. F.

Tecnologias limpas: uma postura empresarial. In: ENCONTROANUAL DAANPAD, 17., 1997, Rio de Janeiro. Anais ... Rio de Janeiro: ANPAD, 1997. CDROM.

ROHRICH, S. S.

A relação entre gestão ambiental e inovação tecnológica em organizações industriais. 2001.157f. Dissertação (Mestrado em Administração) - Universidade Federal do Paraná. Curitiba.

SANCHES, C. S.

Gestão ambiental proativa. Revista de Administração de Empresas, São Paulo, v. 40, n. 1, p. 76-87, jan./mar. 2000.

\section{SCHMIDHEINY, S.}

Mudando o rumo. Rio de Janeiro: FGV, 1992.

\section{VENSKE, C.S.}

A situação do ecodesign em empresas moveleiras da região de Bento Gonçalves, RS: análise da postura e das práticas ambientais. 2002. $126 \mathrm{f}$. Dissertação (Mestrado em Administração) - Universidade Federal do Rio Grande do Sul. Porto Alegre.

\section{VIEGAS, C.;}

FRACASSO, E. M.

Capacidade tecnológica e gestão de resíduos em empresas de calçados do Vale dos Sinos : Estudo de dois casos. Revista de Administração Contemporânea, Curitiba, v. 2, n. 2, p. 41-62, maio/ago. 1998. 